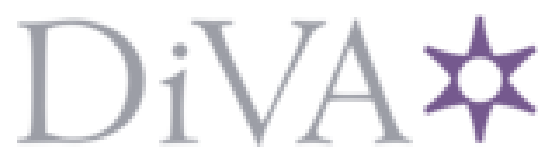

http://www.diva-portal.org

This is the published version of a paper published in Traffic Injury Prevention.

Citation for the original published paper (version of record):

Viklund, Å., Björnstig, J., Larsson, M., Björnstig, U. (2013)

Car Crash Fatalities Associated With Fire in Sweden.

Traffic Injury Prevention, 14(8): 823-827

http://dx.doi.org/10.1080/15389588.2013.777956

Access to the published version may require subscription.

N.B. When citing this work, cite the original published paper.

Permanent link to this version:

http://urn.kb.se/resolve?urn=urn:nbn:se:umu:diva-84812 


\title{
Car Crash Fatalities Associated With Fire in Sweden
}

\author{
ÅSA VIKLUND ${ }^{1}$, JOHANNA BJÖRNSTIG ${ }^{2}$, MAGNUS LARSSON ${ }^{1,3}$, and ULF BJÖRNSTIG ${ }^{2}$ \\ ${ }^{1}$ The Swedish Transport Administration, Luleå, Sweden \\ ${ }^{2}$ Department of Surgery/KBC, Umeå University, Umeå, Sweden \\ ${ }^{3}$ Norwegian Public Roads Administration, Region East, Lillehammer, Norway
}

Received 4 October 2012, Accepted 16 February 2013

Objective: To study the epidemiology and causes of death in fatal car crashes on Swedish roads in which the victim's vehicle caught fire.

Methods: The data set is from the Swedish Transport Administrations in-depth studies of fatal crashes 1998-2008. Autopsies from all cases provided data on injuries, toxicological analyses, and cause of death.

Results: In total, 181 people died in 133 burning cars, accounting for 5 percent of all deaths in passenger cars, sport utility vehicles, vans, and minibuses during 1998 to 2008. The cause of death for a third of the victims was fire related, as burns and/or smoke inhalation injuries, with no fatal trauma injuries. Twenty-five of these 55 deaths were persons 19 years or younger and included 15 of 18 rear seat deaths.

Over half of the 181 deaths were in vehicles that had collided with another vehicle and, of these cases, half were killed in collisions with heavy vehicles. The percentage of drivers with illegal blood alcohol concentrations $(27 \%)$ and suicides $(5.5 \%)$ were not higher than in other fatal crashes on Swedish roads. The ignition point of the fire was indicated in only half of the cases and, of those, half started in the engine compartment and one fourth started around the fuel tank or lines.

Conclusions: Car fires are a deadly postcrash problem. Reducing this risk would be primarily a responsibility for the automotive industry. A multifactor approach could be considered as follows: risk-reducing design, insulation, reduced flammability in motor compartment fluids and plastics, and automatic fire extinguishing equipment. Inspiration could be found in how, for example, the auto racing and aviation industries handle this problem.

Keywords: vehicle fire, fatality, death rate, burns, smoke inhalation

\section{Introduction}

Attention to car fires has varied over the decades. In the late 1960s, this problem was increasingly recognized. In the United States, this contributed to a gradual increase in demands for road vehicle safety manifested in the Federal Motor Vehicle Safety Standard (FMVSS 301) (NHTSA 1998). The first standard was implemented in 1967 focusing on fuel-induced fires beginning with model year 1968 (Malliaris 1991). FMVSS 301 was later supplemented and refined, and in 1972 FMVSS 302 was implemented, focusing on "flammability of interior materials in vehicles," with the aim of reducing interior fires (NHTSA 1998). However, the standards did not have full effect until model years 1976-1978. Some authors reported that these standards have contributed to reducing fire risk in vehicles, both in general and in crashes (e.g., Malliaris 1991). Other authors, however, did not observe this effect (Moore 1989; Parsons 1990). Conditions in Sweden (9 million inhabitants) are currently unknown.

(C) Åsa Viklund, Johanna Björnstig, Magnus Larsson, and Ulf Björnstig

Address correspondence to Ulf Björnstig, Department of Surgery/KBC, Umeå University, SE-901 87 Umeå, Sweden. E-mail: ulf.bjornstig@surgery.umu.se
One of the automotive safety pioneers in the United States, Dr. W. Haddon Jr., has highlighted postcrash fires as a particular deadly postcrash problem. He laid much of the blame on automotive design when he stated, "Those who decide the vulnerability of fuel tanks and fuel systems to crash forces have not done their job responsibly" (Haddon 1980, p. 57).

In the United States, Digges et al. (2003) indicated that approximately 3 vehicles per 1000 involved in some sort of crash catch fire. For fatal crashes, the corresponding figure was 26 fires per 1000 vehicles. During the first decade of the 21 st century, an estimate of the death rate where burns and smoke inhalation were the cause of death indicates a slightly decreasing trend, with about 300 deaths per year in automobile highway crashes in the United States (Ahrens 2008, 2012). The annual property damage cost for automobile fires caused by highway crashes in the United States is estimated at more than half a billion U.S. dollars (Ahrens 2008). There are studies suggesting that older vehicles are more prone to catch fire (e.g., Parsons 1990), but these studies are often older and probably do not represent today's vehicle fleet.

Given that the engine area of today's cars is packed with hot components, fuel lines, different flammable oils, plastic, washer fluid, and electronics, all of which may contribute to increased fire risk, studying fatal car crash fires in a modern car park may be of interest. 
Aim

The aim of this study was to analyze the epidemiology of fatal car crashes on Swedish roads in which the vehicle of the deceased caught fire. This may give a basis for assessing the size of the problem in a European context and the need for fire prevention and mitigation measures.

\section{Materials and Methods}

Since 1998, the Swedish Transport Administration (formerly National Road Administration) has collected in-depth study data from all fatal road traffic incidents in Sweden. The database has not been completely computerized, so the present data were extracted manually from the data files for the years 1998-2008.

The selection criteria were that fire occurred at the incident in the victim's vehicle (passenger car, sport utility vehicle, van, or minibus). In Sweden, a minibus may transport a maximum of one driver and 8 passengers. Drivers possessing a passenger car license are allowed to drive all of these types of vehicles. All events and data were reevaluated by the authors. All victims were autopsied and the cause of death was given in the death certificate. By regulation, a full autopsy is the standard in Sweden for fatal traffic incidents, including suitable toxicological analyses; for example, drivers' blood alcohol concentration (BAC) and burn victims' hemoglobin carbon monoxide ( $\mathrm{HbCO}$ ) concentration. The cause of death is determined by the forensic pathologist after weighing all factors observed.

Three motorcyclist fire-related deaths following collisions with other vehicles, where the vehicles caught fire, were not included in the analysis.

After reevaluation, the material included 181 casualties; all were occupants of burning vehicles suffering burns and/or smoke inhalation injuries.

Qualified specialist investigations of the cause of fire were not done in most cases, and these data relies on witness accounts and judgment by the crash investigators.

\section{Results}

\section{All Fatalities}

During the 11-year study period, 181 persons died in 133 different road crashes in which the victims' vehicles caught fire. In 1999, twice as many persons were killed in burning vehicles compared to the average for the other years (see Figure 1). Contributing to this were 2 severe crashes in which several minors were involved. One was a minibus transporting children and adolescents that collided with a truck and one was a van and passenger car collision where both vehicles were transporting multiple children in rear seats. The total annual number of crash fatalities on Swedish roads in the actual type of car vehicles is also shown in Figure 1; in total 5 percent died in burning vehicles.

Collisions with other vehicles resulted in 101 (56\%) fatalities, $79(43 \%)$ fatalities occurred in single-car crashes, and one person died in a crash with a moose. Of the 101 collision

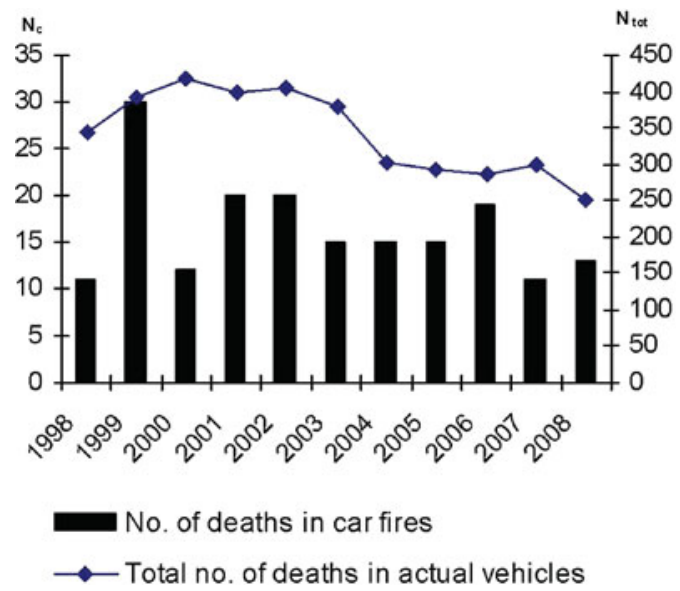

Fig. 1. Number of deaths in car fires $\left(N_{c}\right)$ and total number of deaths $\left(N_{\text {tot }}\right)$ in the actual vehicles during the study period (color figure available online).

deaths, 47 were killed in crashes with heavy vehicles, mostly trucks, and 4 of these were rear-end impacts to the victim's car. Of the total 181 fatalities, $118(64 \%)$ were drivers, 23 $(12 \%)$ were front seat passengers, and $28(15 \%)$ were rear seat passengers, of whom 20 were aged 19 or younger. In $12(7 \%)$ cases, the seating position was unknown. A majority (140, $77 \%)$ were male, and $41(23 \%)$ were female. The death rate was highest for the age group 20-29 (53,29\%); see Table 1 .

Two thirds were killed on high-speed roads with a speed limit of $110 \mathrm{~km} / \mathrm{h}(30,16 \%)$ or $90 \mathrm{~km} / \mathrm{h}(94,52 \%)$. Forty-one $(23 \%)$ were killed on $70 \mathrm{~km} / \mathrm{h}$ roads and $14(8 \%)$ on $50 \mathrm{~km} / \mathrm{h}$ roads. In two cases speed limit information was missing. In at least $72(39 \%)$ cases, seat belts or child restraints had been used; in $50(28 \%)$ restraints had not been used, and in $59(32 \%)$ cases the seat belt use was unknown. Only 3 of the 17 crash victims who were partly or completely ejected from burning vehicles died from burn injuries. All 3 burn injury deaths were persons trapped under the vehicles. In the 14 remaining cases the cause of death was traumatic injuries.

Thirty-two $(27 \%)$ of the 118 drivers killed had a BAC+ above 0.2 per mille (the legal limit in Sweden) at autopsy. In 3 $(3 \%)$ cases the BAC was between 0.12 and 0.16 per mille, and in $73(62 \%)$ cases no alcohol was detected. In $11(9 \%)$ cases BAC data were missing: 4 due to hospital treatment before death

Table 1. Distribution of the number of deaths for male and female occupants, by age group

\begin{tabular}{lccr}
\hline Age (years) & Female & Male & Total \\
\hline $0-9$ & 6 & 7 & 13 \\
$10-19$ & 6 & 27 & 33 \\
$20-29$ & 12 & 41 & 53 \\
$30-39$ & 8 & 25 & 33 \\
$40-49$ & 3 & 17 & 20 \\
$50-59$ & - & 9 & 9 \\
$60-69$ & 2 & 8 & 10 \\
$70+$ & 4 & 4 & 8 \\
Unknown age & - & 2 & 2 \\
Total & 41 & 140 & 181 \\
\hline
\end{tabular}


(BAC is not routinely tested in Swedish hospitals), 4 because too much blood had been lost to get a relevant sample, and in 3 cases the bodies were so severely burned that representative samples were not obtained.

Of the 181 deaths, one third perished in cars older than model year $1990(60,33 \%)$, nearly half in cars from 1990-1999 $(85,47 \%)$, and one fifth $(36,20 \%)$ in cars from model years 2000-2006.

The source of the fire was not stated in half $(69,52 \%)$ of the 133 cases, but in at least $31(23 \%)$ vehicles the fire ignited in the engine compartment, and in $16(12 \%)$ cases (of which 2 cars were rear ended) it started around the fuel tank. At least $15(11 \%)$ fires had other origins; for example, other burning cars or burning ground vegetation ignited by the catalysts. In one of these 15 cases, witnesses stated that flames had been seen in the passenger compartment before the crash. In one case a $10-\mathrm{L}$ gasoline container without lid was transported in the passenger compartment, contributing to a violent fire.

In $14(11 \%)$ crashes other road users quickly started firefighting and rescue but with limited success.

\section{Cause of Death}

In $118(66 \%)$ cases the primary cause of death was traumatic injuries and in $55(30 \%)$ cases the fire (burns and/or smoke inhalation) was the primary cause of death. In $8(4 \%)$ cases, the autopsy could not to give a single clear cause of death. The forensic pathologist and police found clear evidence of suicide in 5 cases $(3 \%)$ and suspected suicide in another $5(3 \%)$ cases; all of these cases were lone occupants.

Fatal traumatic injuries were associated with high crash violence resulting in multiple severe injuries, such as rupture of the aorta, tearing of the heart, massive lacerations of various internal organs or body parts, fracture of the cervical spine, etc.

Of the 55 fire-related deaths, 39 (71\%) were caused only by fire and smoke, and in $16(29 \%)$ cases the cause of death was the fire with contributions from incurred trauma.

\section{Deaths Caused by Fire}

The cause of death for the 55 persons in 32 vehicles who died due to the fire was as follows:

- $41(75 \%)$ : burn injuries ( $\mathrm{HbCO} 2-41 \%)$

- $10(18 \%)$ : combination of smoke inhalation + burn injuries $(\mathrm{HbCO} 18-42 \%)$

- 3 (5\%): smoke inhalation ( $\mathrm{HbCO} 22-29 \%)$

- $1(2 \%)$ : smoke inhalation $(\mathrm{HbCO} 62 \%)+$ poisoning by Zipiklon $(2.1 \mu \mathrm{g} / \mathrm{mL})$, a "sleeping pill"

The cause of death for those in the smoke inhalation groups is based on specialist judgment, including not only findings of toxic substances in the blood but also, for example, smoke deposits in the lower airways, bronchioles, and alveoli plus edema and burns in the lower airways.

Of the 55 fire-related deaths, $38(69 \%)$ victims were male and $17(31 \%)$ were female. Nearly half of them $(25,45 \%)$ were children or adolescents aged 19 or younger; see Table 2.
Table 2. Distribution of male and female deaths, by age group, where the primary cause of death was burn injuries and/or smoke inhalation

\begin{tabular}{lccr}
\hline Age (years) & Female & Male & Total \\
\hline $0-9$ & 4 & 5 & 9 \\
$10-19$ & 4 & 12 & 16 \\
$20-29$ & 1 & 9 & 10 \\
$30-39$ & 4 & 6 & 10 \\
$40-49$ & 1 & 2 & 3 \\
$50-59$ & - & - & - \\
$60-69$ & 1 & 1 & 4 \\
$70+$ & 2 & 38 & 3 \\
Total & 17 & & 55 \\
\hline
\end{tabular}

Twenty-five (45\%) were drivers and $30(55 \%)$ were passengers (18 rear seat passengers, of whom 15 were aged 19 or younger; 7 were front seat passengers; and in 5 cases the seating position was uncertain). Eleven (44\%) of the 25 drivers killed had a BAC above the legal limit. Seat belts/child restraints had been used by at least $27(49 \%)$. One specially restrained disabled person, transported in a minibus, perished because he could not abandon the burning vehicle.

Half of the 55 deaths occurred in cars from model years $1990-1999(27,49 \%)$, one third $(18,33 \%)$ in cars older than model year 1989, and $10(18 \%)$ in cars newer than model year 2000.

Thirty (55\%) were killed in single-car crashes and $25(45 \%)$ in collisions with other vehicles, of which 19 were frontal crashes with oncoming vehicles. Three fire deaths in 2 crashes were caused by rear-end impacts, both from trucks. In these cases, the fire started around fuel spill from the tank. The cars were 1988 and 1994 models, respectively. These car models were not sold in the United States. In $3(5 \%)$ cases rescue and firefighting started quickly by other road users; in one case an ambulance crew took part.

Of the 32 vehicles that caught fire, the fire's origin was uncertain in half of the cases $(16,50 \%)$. However, in at least $7(22 \%)$ cases the fire started around the fuel tank, in $5(16 \%)$ cases the fire started in the engine compartment, and in 4 cases the fire had other origins; for example, from the ground vegetation (probably initiated from hot catalyst). In one case, the fire had started in the passenger compartment prior to the car leaving the road and crashing at high speed on a $110 \mathrm{~km} / \mathrm{h}$ highway. Witnesses stated that the car was completely in flames before it had come to rest. The case with $10 \mathrm{~L}$ of gasoline in a lidless container in the passenger compartment also died because of severe burns.

\section{Case Reports-Multiple Child Deaths by Fire}

Two multifatality cases from 1999, one involving a van and the other a minibus, are presented in this section.

In the first case, a passenger car crashed into the side of an oncoming van and both vehicles burst into flames. In the van, 5 people were killed, 4 of whom were children 1-9 years old, and in the passenger car 3 people were killed, 2 of whom were children (6 and 9 years old). All used seat belts. All 8 died as a result of the fire, with no fatal trauma injuries. 
In the second case, a minibus crossed over into the oncoming lane and collided with the side of a truck. Both vehicles caught fire and 9 people in the minibus were killed. The victims were aged 12-36, 7 of whom were children/adolescents $12-15$ years of age. All occupants were wearing seat belts. Despite this, the 3 front seat occupants were ejected from the vehicle. The cause of death for these 3 was traumatic injuries, and the other 6 children/adolescents (12-13 years) had firerelated causes of death with no fatal trauma injuries.

\section{Discussion}

A total of 181 people were killed in 133 fire-related crashes, which is 5 percent of the total 3767 passenger car, sport utility vehicle, van, and minibus ( = cars) occupants killed during the 11 years surveyed. This is an annual rate of about 4 per million cars in traffic, equivalent to about 0.3 deaths in burning cars per $10^{9} \mathrm{~km}$ driven. About 30 percent of these deaths were fire related without other fatal trauma injuries; of these, nearly half were children and adolescents aged 19 or younger. Some of the crashes were multifatality crashes with up to 9 killed; most of these deaths were caused by fire or smoke inhalation. In other crashes without fire during the study years, no more than 5 people were killed in any one crash. Fire is one of the most frequent causes of multifatality road incidents worldwide, also typically in buses and coaches (Björnstig and Forsberg 2010).

Alcohol-inebriated drivers (27\%) were less common in these crashes than in a total material of passenger car crash victims (39\%) from northern Sweden during 2005-2006 (Björnstig et al. 2008, Ahlm et al. 2009). Suicide was verified or suspected in $10(5.5 \%)$ of 181 cases in our series, which is comparable with 4.4 percent in fatal passenger cars collisions (Björnstig et al. 2008), or 5 percent of all fatal motor vehicle deaths in Sweden (Ahlm et al. 2001). In Finland the corresponding figure is 5.9 percent (Hernetkoski and Keskinen 1998). Consequently, none of these factors were overrepresented in our data set.

Two thirds of the fatalities occurred on high-speed roads with a speed limit $90 \mathrm{~km} / \mathrm{h}$ or higher, indicating high-impact force and deformation. More than half of all deaths occurred in multivehicle crashes, and in almost half of these deaths the collision was with a heavy vehicle such as a truck. With greater forces, the risk that car body safety zones are destroyed and flammable substances are spread and ignited probably increases (Parsons 1990).

There are almost 100 different FVMSSs (National Highway Traffic Safety Administration 1998), but only a few address fire risks. FMVSS 301 sets the standard for making fuel systems safe and FMWSS 302 addresses flammability and burn rate of vehicle interior materials. According to Digges et al. (2008) and Digges and Stephenson (2009), these may be considered for revision and better adapted to modern construction and materials. Gasoline is not the only problem; many other motor fluids such as servo and brake fluid, motor oil (all with auto ignition temperature about $200^{\circ} \mathrm{C} / 400^{\circ} \mathrm{F}$ ), alcohol in windshield wiper fluid, etc., may be highly flammable during the extreme circumstances of a crash. Digges et al. (2008) have reported from the United States that interior material is important for human survival in burning vehicles. Strangely, the interior material requirements for cars are in many respects lower than, for example, the requirements for aircraft, ships, and home furniture. In this data set there was one case in which witnesses reported a fully developed fire in the car before the crash (anecdotally, fires starting in the AC fan of this model have occurred); however, the crash investigation was not conclusive in this respect. Manufacturers' recalls for eliminating a fire risk are not possible to check in a register in Sweden, as it is in, for example, the United States.

About a third ( 55 persons) of the crash victims died mainly from burns and/or smoke inhalation and not due to trauma from the crash. Of these, $30(55 \%)$ were passengers; 18 rear seat passengers. The risk for fatal traumatic injuries is 26-37 percent lower in the rear seat (Evans 2004), making fire and smoke inhalation particularly harmful for these, often young (15 of 18 were aged 19 or younger), persons. Two thirds of all victims in rear seats had fire-related causes of death, without fatal traumatic injuries. This may also indicate rear seat evacuation problems after crashes with subsequent fires. Vans and minibuses may be worst, which is illustrated by the 2 worst multifatality crashes in this data set.

Where the vehicle fire initiated is not well elaborated in these crash investigations, leaving uncertainty regarding the ignition point in half of the cases. In cases with known fire ignition points, nearly half started in the engine compartment and one fourth around the fuel tank. A report from the United States also had problems identifying the ignition point in 23 percent of the cases (U.S. Department of Homeland Security 2008). In another U.S. study, Digges et al. (2003) reported that two thirds started in the engine compartment and 11 percent around the fuel tank. Special field studies of cars catching fire have the potential to give a much more detailed picture of what actually happened (Scheibe et al. 1999). It would be of significant value to engage professional fire investigators on the crash investigation teams in these cases to identify ignition points and to give a basis for adequate preventive measures.

An effective fire extinguishing system would have a potential to reduce the fire risk. In car racing, since the late 1960s, Halon - a liquefied compressed gas, simple to use, clean, requiring small storage space, and providing good protection - has been seen as the ultimate extinguishant (Curry 1972). However, Halon has been phased out because of its contribution to ozone layer depletion. Since 2008 it has also been forbidden in auto racing. Alternatives such as powder and aqueous foams have several drawbacks; for example, they are "dirty" and may be difficult to apply over the whole fire area, especially in hidden areas. Furthermore, the powders are corrosive and are an inhalation hazard for occupants and rescuers. However, it is hoped that the industry will soon develop substitutes with characteristics similar to Halon; for example, DuPont FE-36T (Hammel 2008).

The strengths of the present study are the high quality of the Swedish in-depth study system, which includes all fatal road incidents, and Swedish law making a full autopsy routine. The weakness is the lack of professional fire investigators in the team - a necessity to improve the fire investigation process and a prerequisite for finding the exact cause of the fire. That the 
restraint use data had a considerable number of unclassified cases was disturbing. This may be a sign of neglect to perform an all-embracing data collection in these cases. This was most pronounced during the first years after the in-depth studies started.

This study thus indicates the necessity of better fire investigation capacity of the in-depth study multiprofessional teams. Passenger cars would benefit from incorporating a modern fire-resistant design, reduced flammability of fluids and insulation, and an effective fire suppression or extinguishant system. Based on the indications of our data, this could potentially save many people. Survival time in a burning vehicle is so short that it is not realistic to expect help from the fire brigade. Eventually, other road users with access to a fire extinguisher may help; however, the success rate is probably low, as indicated in some of our cases.

\section{Acknowledgment}

Thanks to the deep study groups in The Swedish Transport Administration for providing data on these crashes and to Loren Gill for language revision.

\section{References}

Ahlm K, Björnstig U, Öström M. Alcohol and drugs in fatally and nonfatally injured motor vehicle drivers in northern Sweden. Accid Anal Prev. 2009;41:129-136.

Ahlm K, Eriksson A, Lekander T, Björnstig U. All traffic related deaths are not "accidents" - an analysis of official Swedish statistics. The Journal of Swedish Medical Society. 2001;98:2016-2022.

Ahrens M. US Vehicle Fire Trends and Patterns. Quincy, MA: National Fire Protection Association; 2008.

Ahrens M. Automobile fires in the US: 2006-2010 estimates. Paper presented at: 2nd International Conference on Fires in Vehicles; September 27-28, 2012; Chicago, IL.
Björnstig U, Björnstig J, Eriksson A. Passenger car collision fatalities - with special emphasis on crashes with heavy vehicles. Accid Anal Prev. 2008;40:158-166

Björnstig U, Forsberg R. Transportation disasters. In: Koenig EL, Schultz CH, eds. Disaster Medicine. New York, NY: Cambridge University Press; 2010:267-273.

Curry TH. Halon 1301 protects racing cars. Paper presented at: National Fire Protection Association (NFPA) Annual Meeting; May 15-19, 1972; Philadelphia, PA.

Digges KH, Gann RG, Grayson SJ, et al. Human survivability in motor vehicles fire. Fire Mater. 2008;32:249-258.

Digges KH, Stephenson RR. Fireworthiness: a final report on the technology base. 2009. Available at: http://www-nrd.nhtsa.dot.gov/pdf/ esv/esv21/09-0211.pdf. Accessed December 3, 2012.

Digges KH, Stephenson RR, Bedewi PG. Fire safety performance of motor vehicles in crashes. Paper presented at: 18th International Technical Conference on the Enhanced Safety of Vehicles; May 19-22, 2003; Nagoya, Japan

Evans L. Fatalities according to seating position. In: Traffic Safety. Bloomfield Hills, MI: Science Serving Society; 2004:54.

Haddon W. Options for the prevention of motor vehicle crash injury. Isr J Med Sci. 1980;16:45-68.

Hammel HS. The change from Halon in the auto racing industry. Available at: http://www.nfpa.org/assets/files/PDF/Foundation \% 20proceedings/Hammel.pdf. Accessed September 2012.

Hernetkoski K, Keskinen E. Self-destruction in Finnish motor traffic accidents in 1974-1992. Accid Anal Prev. 1998;30:697-704.

Malliaris AC. Impact-induced car fires - a comprehensive investigation. Accid Anal Prev. 1991;23:257-273.

Moore G. Growing problem of road vehicles fires. Fire Prev. 1989;222:29-31.

National Highway Traffic Safety Administration. Federal Motor Vehicle Safety Standards and Regulations. Washington, DC: US Department of Transportation; 1998

Parsons GG. Motor Vehicle Fires in Traffic Crashes and the Effects of the Fuel System Integrity Standard. 1990. Washington, DC: US Department of Transportation, NHTSA Report Number DOT HS 807-675.

Scheibe RR, Shields LE, Angelos TE. Field investigation of motor vehicle collision-fires. Paper presented at: 1999 SAE International Congress and Exposition; March 1-4, 1999; Detroit, MI.

US Department of Homeland Security. Highway vehicle fires. Topical Fire Report Series. 2008;9:1-11. 